\title{
A Brief Foray into Social Inclusion- what does it mean for professional health practice?
}

\section{Lynne Briggs}

Griffith University

\section{Paul Harris \\ Griffith University}

\begin{abstract}
The aim of this paper is to stimulate debate around the concept of 'social inclusion' in the context of working in health care. A perusal of the literature shows the terms social inclusion, social capital and social participation are often used synonymously giving rise to questions as to what these terms actually mean. That is, are they all one and same thing, or are they different concepts, and how do they relate in the professional practice arena? To ensure there are core understandings about these terms initially some definitions of social inclusion and exclusion are offered. Some social issues are also briefly presented to illustrate how social, inclusion or exclusion, policies and practices can impact on individuals, families and communities.
\end{abstract}

Keywords: Social Inclusion, social participation, social capital, health and wellbeing, resettlement

Essentially, social inclusion and social exclusion provide descriptions about the differing components of a society, that is what is included or valued and what is excluded or devalued. Historically, some studies have examined exclusion from public and private services while others have focussed on social relations and participation in social activities and culture. What is needed now is more rigorous research that both refines and develops reliable methodologies for measuring social inclusion and social exclusion in different contexts, including in relation to health differentials. Since the turn of the century much has been done to advance our understanding of the social determinants of health (e.g. Wilkinson \& Marmot, 2003), however, the implications for practice and systemic changes that are required appear less understood. For instance, the translation of research that promotes understandings of the mechanisms by which social capital and social participation affect health care, health behaviours and health outcomes across groups is required. To address this issue further consideration needs to be given to the origin of the concept 'social inclusion' and how the term is currently embedded within the political and social policy discourse of the Australian health system.

Corresponding author: Lynne Briggs (I.briggs@griffith.edu.au)

As a starting point for this investigation we need to understand how we, as health practitioners, can support the health and wellbeing of all health consumers. An understanding of health differentials is one thing but responding to different burdens of 
injury and illness, differences in exposure to risk and protective factors, and different individual preferences and circumstances is another. It is through our own research endeavours that we gain understanding and knowledge which places us in a better position to consider effective means of monitoring, managing risks and promoting protective behaviours that improve health outcomes for all. This is in addition to our responsibilities to be advocating for more policies and practices that ensure social inclusion of all Australians unconditionally.

\section{Definition of Terms}

Throughout the literature the concepts of social inclusion and exclusion are often used simultaneously and interchangeably. As Silver (2010) noted, although often seen differently, social inclusion and exclusion are not the inverse of each other as both processes are interrelated and can occur simultaneously. Social exclusion can be defined as a condition, or an outcome, where excluded individuals or groups are unable to participate fully in society because of their social identity (on the basis of their gender, age, ethnicity, caste, religion or other manifestations of cultural identity), or social location (for example people who live in remote areas, or regions that are stigmatised or suffering from war and conflicts). As Beall and Piron (2005) argue, all of these factors can impact on the interconnections between the country's economy, politics and social participation that results in exclusion of people from organisations, institutions and enjoyment in social life. Silver (2007) also recognises that social exclusion is concerned with the lack of opportunity for full participation in all aspects of community and societal life but also makes the point that although individuals may be excluded in some areas, they may be included in others. Building on and generalising these areas of relative success or strength is the challenge for all health professionals.

Concordantly, the United Nations Educational, Scientific and Cultural Organization (UNESCO, 2012), have defined social inclusion as representing an inclusive society where every individual has a part and an active role to play. Such a society is based on fundamental values of equity, equality, social justice, and human rights and freedoms, as well as on the principles of tolerance and embracing diversity. Cappo (2002) also refers to a socially inclusive society as being one where all people feel valued, their differences are respected and their basic needs are met which allows them to live with dignity. This is an alternative definition to that offered for social exclusion whereby one is shut out from the social, economic, political and cultural systems that contribute to the integration of individuals in a community.

The definitions of social exclusion and inclusion both emphasise the notion of social participation (a term that is also referred to as social engagement and/or, social involvement in the literature). Regardless of the term used, broadly speaking participation relates to the shaping of policies that advance health equity is justified on ethical and human rights grounds (World Health Report, 2008). From a strategic point of view the way in which the health system contributes to social participation, and the empowerment of the people, is defined as one of the main aspects for the development of the Primary Health Care strategy (WHO, 2008). The overlap between social participation and social capital (or the value we get from this participation, e.g. levels of trust, reciprocity and the diversity of our networks) is clear, as are the health benefits of having social support and social networks (Berry \& Welsh, 2010). According to Dolfsma and Dannreuther (2003) social capital is used to describe how social networks, or 
groupings of people, allow individuals to achieve things they could not do on their own. Thus, most definitions of social capital focus on the benefits arising from our social participation and relationships. As social capital is associated with better health outcomes, it follows that Berry and Welsh (2010) identified social or community participation as something that is not only amenable to intervention but effective in promoting social cohesion, mental health and wellbeing more broadly.

Social capital and health research has emerged as a focus of contemporary behavioural epidemiology in response to the growing recognition of the need to address the social determinants of health and their role in health inequalities (e.g. Kaljee \& Chen, 2011,). If we look more specifically at research into health care, is it important to understand how the social determinants of health reflect the different conditions that people are born, grow up, work, live and age with and how these shape or constrain opportunities for social inclusion, across the lifespan. Social inequities in health - the unfair and avoidable differences in health status across groups in society - are those that result from the uneven distribution of social goods and resources (i.e. social determinants). As such their combined influences either strengthen or undermine the health of individuals and communities. For example, across illness and injury classifications, people from poorer social or economic circumstances are at greater risk of poor health than people who are more advantaged (Wilkinson \& Marmot, 2003).

We also know that a person's health can be influenced by biomedical factors and health behaviours that are part of their individual lifestyle and genetic make-up. These factors can be positive in their effects (for example, being vaccinated against disease), or negative (for example, consuming alcohol at risky levels). To demonstrate the significance of the health inequalities that exist, including in high-income countries such as Australia, it is worth noting the following statistics cited in the latest update of the state of the nation (Australian Bureau of Statistics [ABS], 2016):

- The $20 \%$ of Australians living in the lowest socioeconomic areas in 2014-15 were 1.6 times as likely as the highest $20 \%$ to have at least two chronic health conditions, such as heart disease and diabetes (ABS, 2015a).

- Australians living in the lowest socioeconomic areas lived about 3 years less than those living in the highest areas in 2009-2011 (NHPA, 2013).

- If all Australians had the same death rates as people living in the highest socioeconomic areas in 2009-2011, overall mortality rates would have reduced by $13 \%$-and there would have been 54,000 fewer deaths (AIHW, 2014d).

- People reporting the worst mental and physical health (those in the bottom $20 \%$ ) in 2006 were twice as likely to live in a poor-quality or overcrowded dwelling (Mallett et al., 2011).

- Mothers in the lowest socioeconomic areas were 30\% more likely to have a low birthweight baby than mothers in the highest socioeconomic areas in 2013 (AlHW, 2015a).

- A higher proportion of people with an employment restriction due to a disability lived in the lowest socioeconomic areas (26\%) than in the highest socioeconomic areas (12\%) in 2012 (AlHW analysis of ABS 2012 Survey of Disability, Ageing and Carers).

- Unemployed people were 1.6 times as likely to use cannabis, 2.4 times as likely to use meth/amphetamines and 1.8 times as likely to use ecstasy as employed people in 2013 (AlHW, 2014e). 
- Dependent children living in the lowest socioeconomic areas in 2013 were 3.6 times as likely to be exposed to tobacco smoke inside the home as those living in the highest socioeconomic areas (7.2\% compared with 2.0\%) (AlHW analysis of the 2013 National Drug Strategy Household Survey).

- People in low economic resource households spend proportionally less on medical and health care than other households $(3.0 \%$ and $5.1 \%$ of weekly equalised expenditure, respectively, in 2009-10) (ABS, 2012).

- People living in the lowest socioeconomic areas in 2014-15 were more than twice as likely to delay seeing - or not see-a dental professional due to cost compared with those living in the highest socioeconomic areas (28\% compared with 12\%) (ABS, 2015b).

We also know that there is a strong and persistent association between discrimination and social exclusion. Many exclusionary experiences stem from discrimination of individuals or groups on the grounds of their attributes, or social, economic or physical circumstances. Freedom from discrimination is a recognised determinant of our mental health (VicHealth, 2004). Discriminatory experiences not only impact a person's immediate wellbeing, but longer term can impact on employment and income outcomes, and access to health care and other community supports and services, which furthers the cycle of non-participation and exclusion.

There are two critical questions that, therefore, need to be addressed. The first is to what extent should the concept of social inclusion require a new approach for the health system? The second, in what ways can social workers and human service practitioners begin to contribute towards more inclusive policies and equitable outcomes for all Australians?

\section{Discussion}

Research into social inclusion and social exclusion can be found throughout the international literature. However, as Ryan, Howell, Kern and Lyubomirsky (2007) have argued, in recognition that our subjective well-being is associated with a range of longer term outcomes, one of the most critical aspects in any exploration of social inclusion is health care systems. While the importance of psychosocial pathways is becoming more widely acknowledged, the association between health and different measures of social inclusion remains complex, and is not well understood. Cultural safety perspectives suggest inclusive practices are end-user defined (e.g. Goodman, 2011). This suggests that if health professionals are also end-user focused, their practice will not only be culturally safe but also illuminating in terms of understanding the specific inclusion/exclusion issues of concern. For example, in relation to successful resettlement of migrants and refugees a sense of acceptance, of belonging to a family, a community and to the country of resettlement appears to be essential for wellbeing (Briggs \& Cooper, 2015).

The literature highlights a number of issues which are both common and unique across population groups and issues, however, Silver (2010) suggested that social exclusion is relative and that it can occur in specific contexts with social isolation and disaffiliation, ostracism or rejection, disrespect and discrimination all expressions of exclusion. Prime examples of these aspects are apparent among migrant populations who are attempting to restart their lives in a host country. In the context of people who have resettled, 
studies have demonstrated that problems of unemployment and under-employment have negative impacts on both psychological well-being and adaptation (Aycan \& Berry, 1996). While the effects of unemployment and under-employment tend to be universal, there are also unique issues to be considered. For instance, a key finding emerging from a Canadian study (Briggs \& Cooper, 2015) was that a lack of engagement in employment appropriate to qualifications and skills held impacted on participants' ability to feel accepted by the local community - something to which new arrivals to a host country will be particularly sensitive. Both these common and unique issues reflect key dimensions and drivers of integration into host societies as they enable people to feel a sense of belonging and being a part of a wider community, which in turn is associated with a range of income, education, training and overall social and health benefits. In addition to defining status and identity (which are also strongly associated with health), employment also provides a purpose to life and enables individuals to develop bridging social capital, or extend their relationships with others in society. Indeed, the additional opportunities for social interaction facilitate improve adaptive behaviours in the short term and the economic participation enables social mobility more broadly.

\section{Final thoughts}

The aim of this article was to stimulate debate around the concept of 'social inclusion' and what it means in terms of health practice for all professionals. The importance of social inclusion to our health and wellbeing has long been recognised. While our general health, mental health and overall wellbeing is very much socially determined, all levels of government appear increasingly focussed on individual risks and lifestyle factors (Lin \& Fawkes, 2007). Indeed, this dilemma and its associated tension have since been identified as a primary source of moral distress for health professionals (Sunderland, Harris, Johnstone, Del Fabbro, \& Kendall, 2014). Is it really surprising, despite the significant investment, good work and good practice that has been identified, in particular, in partnership with the community sector to improve Indigenous health, education and employment outcomes in Australia, that ten years on we are still looking to make significant inroads against the targets identified to Close the Gap (in disadvantage) without corresponding structural reforms? If we are to be effective in closing the gap and reducing health inequalities, more broadly, critical theory would suggest that little might change if the status quo or prevailing attitudes, power structures and imbalances are maintained.

Clearly, greater awareness and action is required to address social exclusion and its adverse implications and to also realise the benefits of inclusive practices, particularly in the health system. The identification and use of more participatory approaches in health care have been identified as one solution to redressing health inequalities (e.g. Berry \& Welsh, 2010). The Ottawa Charter (WHO, 1986), however, suggests that we not only need to encourage participation and empower to build community capacity and personal knowledge and resources, but we also need supportive policy and legislation; (physical, built and social) environments; and re-orient service approaches. The challenge is to extend the awareness of the social determinants of health beyond the realm of population health professionals to the broader health and community services sector, public and private sectors and the community more broadly. In keeping with this aim, the Journal for Social Inclusion called for articles for a special edition focusing specifically on 'social inclusion in health', however, there was limited interest. This paper has sought to remind researchers in the health and community services sectors of the significance of 
these challenges and the need for more direct and deliberate research as part of academics' efforts to inform more inclusive practices and improved outcomes; particularly in lieu of the prevailing forces reinforcing the status quo. We therefore look forward to seeing more research in this area in future editions of the Journal of Social Inclusion and the wider literature.

\section{Conflict of interest statement}

This paper was reviewed and approved for publication by other members of the Journal's editorial team to avoid the conflict of interest associated with the Editor's coauthorship of this paper. 


\section{References}

Australian Bureau of Statistics. (ABS). 2016. SEIFA tutorial 1-transcript. Introduction to SEIFA. Canberra: ABS.

Australian Institute of Health and Welfare. (2016). Mental health services-in brief 2016. Cat. No: HSE 180 Canberra: AlHW.

Aycan, Z., \& Berry, J.W. (1996). Impact of employment-related experiences on immigrants' psychological well-being and adaptation to Canada. Canadian Journal of Behavioural Science, 28(3), 240-251.

Beall, J., \& Piron, L. H. (2005). DFID social exclusion review. London: London School of Economics, Overseas Development Institute, 2-37.

Berry, H.L., \& Welsh, J. A. (2010). Social capital and health in Australia: An overview from the household, income and labour dynamics in Australia survey. Social Science \& Medicine, 70(4), 588-596. https://doi.org/10.1016/j.socscimed.2009.10.012

Briggs, L., \& Cooper. L. (2015). Demoralization: Exploring the Post-Migratory Experiences of Newcomers Resettling In Canada. Journal of Sociology and Social Work, 3(2), 17-26.

Cappo, D. (2002). Social inclusion, participation and empowerment. Address to Australian Council of Social Services National Congress November, Hobart.

Dolfsma, W., \& Dannreuther, C. (2003). Subjects and boundaries: Contesting social capital-based policies. Journal of Economic Issues, 37, 405-413.

Goodman, D. (2011). Promoting diversity and social justice: educating people from privileged groups, $\left(2^{\text {nd }}\right.$ edition). Routledge: New York.

Kaljee, L.M., \& Chen X. (2011). Social capital and risk and protective behaviours: a global health perspective. Adolescent Health, Medicine and Therapeutics, 2 113-122

Lin, V., \& Fawkes, S. (2007). Health promotion in Australia: Twenty years on from the Ottawa Charter. Promotion \& Education, 14(4), 203-208.

Ryan, T., Howell, M., Kern, L., \& Lyubomirsky, S. (2007). Health benefits: Metaanalytically determining the impact of well-being on objective health outcomes. Health Psychology Review, 1(1), 83-136

Silver, H. (2010). Understanding Social Inclusion and Its Meaning for Australia. Australian Journal of Social Issues, 45(2).

Silver, H. (2007). 'The Process of Social Exclusion: the Dynamics of an Evolving Concept'. CPRC Working Paper 95. Manchester: Chronic Poverty Research Centre.

Sunderland, N., Harris, P., Johnstone, K., Del Fabbro, L., \& Kendall, E. (2014). Exploring health promotion practitioners' experiences of moral distress in Canada and Australia. Global Health Promotion, 22(1), 32-45. doi: $10.1177 / 1757975914532505$

UNESCO. (2015). An indicative review of UNESCO's work on social inclusion. United Nations Educational, Scientific and Cultural Organization, France.

UNESCO. (2012). Social Inclusion, Social Transformations, Social Innovation. Consultations of the Director- General with Member States. November.

VicHealth. (2004). VicHealth Mental Health Promotion Evidence Review: A literature review focussing on the VicHealth 1999-2002 Mental Health Promotion Framework. Retrieved from: https://www.google.com.au/search?q=VicHealth+Mental+Health+Promotion+Evid ence+Review\%3A+A+literature+review+focussing+on+the+VicHealth+1999- 
2002+Mental+Health+Promotion+Framework.+Retrieved +from\%3A\&ie=utf8\&oe=utf-8\&client=firefox-b-ab\&gfe_rd=cr\&ei=kJubWaeBGsXr8AfEk7SACg\#

WHO. (1986). The Ottawa Charter for Health Promotion. WHO: Geneva, Switzerland: Available from:

http://www.who.int/healthpromotion/conferences/previous/ottawa/en/index.html.

WHO. (2013). The World Health Report 2008 - primary Health Care (Now More Than Ever). World Health Organization.

Wilkinson, R., \& Marmot, M. (Ed.) (2003). Social Determinants of Health: The Solid Facts $\left(2^{\text {nd }}\right.$ edn.). World Health Organisation, Regional Officer for Europe: Copenhagen, Denmark. 